\title{
Editorial: Learning in times of crisis
}

\author{
Henning Salling Olesen
}

Roskilde university, Denmark (hso@ruc.dk)

Silke Schreiber-Barsch

Hamburg University, Germany (silke.schreiber-barsch@uni-due.de)

Danny Wildemeersch

Leuven University, Belgium (danny.wildemeersch@kuleuven.be)

The COVID-19 pandemic that has hit the world on an unprecedented scale, in spite of repeated early warnings (Waller et al, 2020), has made many of us aware of the fragility of health systems, economic systems, social systems and the effects on individual lives worldwide. Crises in general are said to be opportunities to reconsider what has been taken for granted for a long time. The pandemic will probably be looked back upon as a historic moment, 'one that could be seen either as an important turning point for humanity or as a huge missed opportunity, a milestone in the story of our deterioration and mismanagement of the planet' (Stanistreet et al, 2020, p. 627). However, turning crises into opportunities necessarily involves processes of learning on an individual and a collective level. In the last eighteen months we have witnessed how experts, politicians, civilians have been coping with unexpected challenges and a persisting uncertainty, while trying to control and overcome increasing death rates, economic disasters, psychological disorders. Scientists have done unprecedented efforts to successfully develop vaccines. Policy makers have installed innovative vaccination programs executed by large numbers of health workers and volunteers.

The impacts of the COVID-19 pandemic have turned into a massive learning experience on a global scale. This has inspired many of us to reflect on the nature of that learning. We have asked questions such as how do we learn? What do we learn? How do crises trigger learning - or hinder learning? And, what role does/can or even should adult and continuing education play in this? In spite of their relative absence from the public debate, (adult-)educationalists have already raised important questions and given answers. Many of them have pointed to the negative educational effects of this crisis for

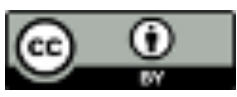


vulnerable groups, creating new inequalities or deepening existing class divides (Käpplinger \& Lichte, 2020, Waller et al, 2020 and English \& Mayo, 2021). Special attention has been paid to the discriminating effects of a long period of online learning, whereby students have dropped out of educational programs or have had great difficulties to stay in, due to the lack of suitable online study conditions. 'While some, educators and students, can teach/learn online from the comfort of their home, many others need to be relieved of their overcrowded spaces and attend to family livelihood concerns including "hidden economy" engagement' (English \& Mayo, 2021, p. 120). Such reflections have inspired us to compose a thematic issue about how and what we learn, not only in COVID19 times, but more generally in the context of disruptive societal crises such as financial crises, unemployment crises, health crises, environmental crises or crises in the lifecourse. We thereby wanted to pay specific attention to the learning and educational processes of adults in formal, non-formal and informal contexts.

Our starting point was that human learning processes are basically rooted in life experiences - both the sedimented and reflected summaries of one's overall life course, and the current experiences. In general, our daily lives are characterized by relatively strong routines that help to make life clear and obvious. This shapes a perception of the world that connects the understanding of the objective world, the relationships with other people and possible futures, as a reality that one can and often has to relate to. Early in life, most children acquire some kind of ontological security: a certainty about who they are, where and how they are grounded in their lived environment. This forms the basis for everyday life experiences, identity processes and a capacity for imagination.

This everyday life consciousness is often collectively supported through shared understanding and mutual identification. Crises then are situations that seriously, often all of a sudden, irritate this relatively certain conception of reality: changes in the objective world, in one's space for possible actions, in one's relationships. There are individual crises that "only" relate to personal life, such as a serious life-changing illness, a divorce or being made redundant in the world of work. But what interested us particularly are those sudden changes in societal conditions that also shake individual and micro-social relationships, the COVID-19 pandemic being a clear example: personal life planning became redundant from one day to the other, people getting unemployed suddenly, or having to work from home in combination with family care, schools being closed and, in certain countries people were not even allowed to leave their homes, apart from purchasing necessary supplies. These kinds of crises have indeed the potential to provide new insights, change routines, enhance utopias or develop new practices that would have been unimaginable before. Crises, thus, may elicit a process of recognition, integrating new knowledge, emotional commitment and notions of what it means for oneself, but also for a collective situation and life practices of humankind. Yet, it is far from evident that the people involved in crises learn anything. They may hope that "business as usual" is reinstalled as soon as possible. A crisis can be so emotionally overwhelming that all attention is concentrated on defense mechanisms. This could even feed into highly irrational and destructive social currents. Insights into these dynamics may help educators in the first place, but also different kinds of experts and policy makers to improve and broaden their repertoire of action.

The latest pervasive crisis is the COVID-19 pandemic. This pandemic has two layers that are intertwined. Basically, the cause of the crisis is biological: a disease threat. The fact that an infectious virus creates a pandemic disease has to do with both its biological functioning and our lack of knowledge of it (infectiousness, long incubation period with unknown level of infection, an unknown diversity in disease course), but also with social conditions. Globalization has dramatically shortened the path from a Chinese food market 
to the whole world. But apart from societal conditions that have facilitated the pandemic impact of this virus, the second layer of the crisis is the political handling of the threat in the form of drastic national lockdowns in large parts of the world - first, in China, then in the Asian neighboring countries, and finally in Europe and other parts of the world.

There is little doubt that the pandemic leaves strong experiences. Entire populations have become amateur epidemiologists. But that does not mean that the most important experience is about viruses. The Corona pandemic is perhaps more anxiety-provoking than many other infectious diseases by its novelty and by its very diverse disease-causing nature. Even at a low "pressure of infection" there is a basis for individual anxiety. Taken together, it creates an ontological insecurity, which enables a potential for projecting a wide range of (other) anxiety-provoking conditions on this disease - that is, a "condensation" of all possible anxiety potentials in relation to this virus. But what experience will the well-founded fear and perhaps more diffuse anxiety leave behind?

There is the peculiarity of a pandemic that the biological threat drastically affects the social: it is social life and the community that become dangerous. In order to control and block this threat, social life must be put under severe control. The nature of the crisis is primarily shaped politically by the definition of the Corona threat and the mitigation strategies used. Institutional and policy interventions have transformed a biological phenomenon into a crisis of social, economic and cultural nature and dimension. This nature of a threat intimately connected to social activity and its contagiousness has secured that also its anxiety-potential has affected everyone. Even though the political reactions have been quite diverse the experience of anxiety has been almost ubiquitous. When we compare with another crises in the relation to nature, the climate crisis, this seems quite different. Although not in the same way as in the COVID-19 pandemic, the ecological crisis, and particularly the crisis of global warming, is a threat arising from the conditions of nature and experienced through an interplay of scientific knowledge, political interpretation and popular opinion. Although there has also been spectacular events - flooding, typhoons, draught and forests burning - that have a lot of attention when they happen, and in spite of the fact that global warming is really a matter of everyday life, it seems that the reactions to these incidents remain passing - people must be reminded by activists in order to keep the awareness awake. The sudden emergence of crisis may give rise to new understandings of expertise and knowledge, and of the (un)controllability of living conditions. One can imagine that the political handling of the threat at national and international level will have an impact on the understanding of the (nation-)state's importance, and thus the crisis will leave quite different, but eventually also common experiences in different countries.

But while the pandemic has been able to label "science" primarily as a potential "cure" (vaccine), science in the climate context is sometimes considered rather as the creator of the crisis when documenting the necessity of uncomfortable and demanding new behavior, and undermining people's understanding of their own opportunities. The scientific documentation of global warming is far less tangible than the illness and death produced by the Corona crisis. It is partly prognostic, it cannot be seen immediately, it is relatively technical and abstract, and appears as a truth that must be accepted because of the credibility of the messenger ("the science") - and has therefore also more easily been the object of denial. Its emotional appeal is limited and its wide-ranging consequences are difficult to understand - for example, how migrant movements are the result of altered climatic conditions. 'Climate change is a pandemic in slow motion' ${ }^{1}$. However, recent floods and forest fires have now brought the experience of global warming close to everyone's livelihoods. 
There is a long tradition in adult education, particularly in citizenship education, sustainability education, workers' education, literacy education, popular education, etc. of dealing with questions on how to enhance the awareness of people concerning major societal issues. Most of these approaches intend to make a connection between individual experiences and societal issues, or try to turn private concerns into public issues and into collective social utopias. Along with these traditions, approaches have been developed in the course of the twentieth century and beyond, that theorize the educational/learning processes related to the development of critical thinking. Various scholars have responded to our invitation to reflect on the role of adult education in connection with individual and collective crises. Below we present five papers that cover different kinds of crisis: unemployment, ageing, environmental and health crises. Two of them are empirical focusing on concrete cases. The other ones are theoretical contributions attempting to broaden and deepen existing concepts, while applying these to the COVID-19 pandemic and its consequences for learning and education.

In 'Creating connections for expansive learning in crisis-laden times of long-term unemployment', Franziska Bonna has chosen the topic of long-term unemployment to explore the impacts and consequences of such highly crisis-ridden situations and their implications for not only the subjects' learning biographies, but also for adult learning and education. Her qualitative study, bringing subject theory (Holzkamp), biographical research (Schütze) and critical theory (Negt) into a conceptual encounter, asks for the existence as well as for the potential of utopian thinking for developing visions of the occupational future in (spite of) the situation of long-term unemployment. By this, Bonna identifies three types of such visions in her interview sample, eliciting the power mechanisms of Germany's neoliberal-driven labour market administration and their impacts on learning biographies as well as subtle traces of utopian thinking. The author argues for recognizing the relevance of these traces in their pivotal role for learning and for the aim of unfolding competencies in an individual and collective situation of societal rupture, calling for a critical-reflexive adult education.

The article on "Age Images and learning in late life. Coping with crisis experiences as a potential in long-life societies" by Claudia Kulmus discusses how experiences from coping with crises in individual life could form a learning potential for learning in and from a societal crises like the actual situation of COVID-19. She points out that the COVID-19 has a specific relation to age, adding a societal disruption to the individual experience of aging. The author presents a qualitative empirical study based on group discussions of elderly people's coping with the fact of aging. A grounded theory analysis of coping strategies shows the cultural structure of individual learning processes in relation to age images and the finiteness of life, and suggests that adult education can support these biographical learning processes. Kulmus discusses these results in relation to the present COVID-19 pandemic, in which also younger people experience the finiteness of life, and suggests that the learning in later life might form a potential for dealing with social crises, particularly in societies characterized by long lives.

The COVID-19 crisis has drawn to our attention that many educational efforts are needed to inform the wider public about the individual and collective risks and the necessary measures to deal with the crisis. Initiatives of 'public pedagogy' are not necessarily one-way operations from scientists and policy makers to the wider public. It is important to turn such dissemination strategies also into transactional processes, involving all stakeholders related to the issue. The vaccination campaigns that have been launched in many countries have shown that particular target groups cannot be reached unless proximity strategies are initiated, while considering the particular cultures and living-conditions of these groups. This is a central argument in Bengtsson and Van 
Poeck's contribution 'What can we learn from COVID-19 as a form of public pedagogy'. In their paper they consider the Corona crisis as a large-scale, unplanned and unintended global experiment of public pedagogy.

Saskia Eschenbacher and Ted Fleming authored 'Toward a Critical Pedagogy of Crisis', exploring the concepts of experience and transformative learning for their role in facing times of crisis and disorientation. To this end, the authors draw upon the works by Oskar Negt, L.A. Paul and René Arcilla in order to shift attention to these conceptual approaches and to review their potential for the pedagogical tasks of adult learning and education. On the basis of their elaboration, the authors encourage a view on experience as a fertile basis for learning and on the understanding that a shared humanity and solidarity might be key to tackle today's existential crisis from the standpoint of adult learning and education.

Traditionally adult education literature theorizes learning in crisis situations with notions such as experiential learning, transformative learning and/or biographical learning. In his contribution 'Learning from the whirlpools of existence: Crisis and transformative processes as complex and rhythmic phenomena', Michel Alhadeff-Jones conceptualizes learning in crisis with the help of complexity theory (Edgar Morin) and his own understanding of rhythms that shape educational processes. In doing so, he problematizes, nuances and enriches classical approaches to transformative and biographical learning in the context of mitigation actions. The contribution concludes by emphasizing the importance of sustaining a critical awareness of the rhythms that shape educational processes in the everyday life, as they reveal the fluidity of ongoing power dynamics.

\section{Notes}

${ }^{1}$ Rob Wijnberg in 'De Correspondent'. https://decorrespondent.nl/11220/waarom-klimaatverandering-eenpandemie-in-slow-motion-is-en-wat-we-daarvan-kunnen-leren/287568600-7a1153b9

\section{References}

English, L., \& Mayo, P. (2021). Lifelong Learning in the Time of Corona 19. In L. English, \& P. Mayo, Lifelong Learning, Global Social Justice and Sustainability, (pp. 117-129). Cham: Palgrave Macmillan.

Käpplinger, B., \& Lichte, N. (2020). The lockdown of physical cooperation touches the heart of adult education. A Delphi-Study on immediate and expected effects of Covid-19. International Review of Education, 66, 777-795.

Stanistreet, P., Elfert, M., \& Atchoarena, D. (2020). Education in the age of Covid 19: Understanding the consequences. International Review of Education, 66, 627-633.

Waller, R., Hodge, S., Holford, J., Milana, M., \& Webb, S. (2020). Lifelong Education, Social Inequality and the COVID-19 Health Pandemic. International Journal of Lifelong Education, 39(3), 243-246. 